\title{
Collective action: fifty years later
}

\author{
Todd Sandler ${ }^{1}$
}

Received: 17 March 2015/Accepted: 21 March 2015/Published online: 9 April 2015

(C) The Author(s) 2015. This article is published with open access at Springerlink.com

\begin{abstract}
This paper presents a retrospective view of Mancur Olson's The Logic of Collective Action. The paper's primary purpose is to investigate the validity of Olson's propositions concerning group size, group composition, and institutional design. This purpose is accomplished by drawing on the literature and the paper's game-theoretic representations. Key considerations behind the validity of his propositions concern benefit rivalry, the aggregation technology, strategic assumptions, and participation costs. The difference between public good and commons games is also an essential consideration. Generally, Olson's propositions fare best for benefit rivalry, a summation aggregator, Nash behavior, and positive participation costs. Because his propositions are true in many important real-world situations, the book remains highly relevant. Efforts to find exceptions to Olson's propositions have served to further our understanding of collective action.
\end{abstract}

Keywords Collective action - Exploitation hypothesis - Selective incentives · Public goods · Commons

JEL Classification D70 $\cdot$ H41 $\cdot$ D62

\section{Introduction}

In 1965, Mancur Olson published The Logic of Collective Action (henceforth, Logic), which is one of the most influential books in the study of public choice. By questioning whether large groups could further their collective interests, Olson (1965) cast group behavior in an unfamiliar light to many-e.g. political scientists and sociologists who viewed groups as necessarily furthering the interests of their members. His provocative

Todd Sandler

tsandler@utdallas.edu

1 Department of Economics, School of Economic, Political \& Policy Sciences, University of Texas at Dallas, 800 W. Campbell Rd., Richardson, TX 75080, USA 
question resonated with public choice scholars, who argued that political agents (e.g. officeholders, voters, lobbies, or political parties) did not always foster collective welfare. ${ }^{1}$ Within the field of economics, Logic influenced the study of key entities in virtually every subfield of economics-e.g. labor unions in labor economics, charities in public economics, cartels in industrial organization, polluters in environmental economics, trading blocs in international economics, sports leagues in sports economics, jurisdictions in regional economics, and alliances in defense economics.

Even though Olson's (1965) group propositions are not airtight, Logic has had a tremendous impact on the study of group behavior. At last count, Logic has amassed almost 29,000 google scholar cites. The book's message transcended economics and altered thinking in sociology, anthropology, political science, and public policy.

Collective action arises when the efforts of two or more individuals or agents (e.g. countries) are required to accomplish an outcome. For instance, oncoming ships at sea must have a convention for avoiding collisions. Additionally, collective action is necessary to attain herd immunity through vaccinations in order to eradicate a disease. Globally, collective action is also required to curb money laundering. Logic demonstrated that individual rationality is not sufficient to achieve collective rationality (Sandler 1992, p. 3). Thus, individuals may pursue self-interested actions that do not further the best interests of the group. ${ }^{2}$ This recognition stands in stark contrast to Adam Smith's invisible hand, where the pursuit of each individual's self-interest in competitive markets bolsters collective well-being. Clearly, Olson's notion of collective action failure is not referring to the provision of private goods in the presence of complete information and unfettered markets; rather, it is concerned with public goods, externalities (i.e. uncompensated interdependencies), and the commons. These latter concerns mean that collective action involves strategic rational choice, better known as game theory (Dixit et al. 2009). In these three market-failure situations, the action of one agent influences and hinges on the decisions of other agents. For a pure public good, one person's contribution automatically benefits other potential contributors owing to nonrivalry and nonexcludability of benefits. Thus, one contributor is likely to reduce his or her contributions as others contribute more to the public good. Similar strategic interactions characterize generators of external benefits or costs, or exploiters in a commons with open access (Ostrom 1990).

If many of Olson's (1965) propositions are not universally valid (Dougherty 2003; Ferguson 2013; Ostrom 2000; Pecorino 2015; Sandler 1992), then why has Logic had such a lasting and profound influence on thought? There are a number of reasons. First, many of Olson's propositions are valid in numerous scenarios with important real-world counterparts, such as the voluntary provision of a pure public good (Bergstrom et al. 1986; Cornes and Sandler 1984, 1996). Second, Olson's bold sweeping maxims taunted readers to find exceptions and, as consequence, to define better boundaries for the practice of collective action (Cornes and Sandler 1984; Esteban and Ray 2001; Ferguson 2013; Marwell and Oliver 1993; Pecorino 2015; Pecorino and Temimi 2008). As Logic's reputation grew,

\footnotetext{
${ }^{1}$ Dougherty (2003) presented a fascinating historical view of collective action traced back to the writings of James Madison, Alexander Hamilton, John Stuart Mill, David Hume, and others. In particular, Dougherty defended the originality of Olson's (1965) Logic in terms of its innovative applications, the exploitation hypothesis, and asymmetric benefits.

2 For example, in a Prisoners' Dilemma game, agents' use of their (rational) dominant strategy results in an outcome with inferior payoffs compared to cooperative outcomes. As a consequence, collective action problems are often tied to Prisoners' Dilemmas (Hardin 1982). This connection can be taken too far because other game structures can be associated with collective action problems (Sandler 1992; Taylor 1987). The importance of game structures for collective action is demonstrated throughout this paper.
} 
researchers' efforts and rewards from finding exceptions to Olson's (1965) maxims took on greater importance. Had Olson presented well-qualified, airtight propositions, the book would have had a smaller following, because the necessary assumptions for universal validity would have placed the book's analysis beyond the reach of the readerships of many related disciplines. ${ }^{3}$ Moreover, these propositions would have applied to a more limited set of practical problems. Third, greater globalization over the last 50 years expanded the importance of the principles and practice of collective action as more countries must interact on a wide range of exigencies involving health, security, governance, financial stability, trade, and the environment. Fourth, countries and cities have grown in size and number, thereby increasing the relevancy of collective action within and among nation-states. Fifth, collective action has assumed novel forms: tracking disease outbreaks, averting climate change, addressing global financial crises, curtailing transnational terrorism, stemming nuclear weapons proliferation, limiting superbugs (i.e. antibiotic-resistant diseases), and preserving unique habitats. Sixth, technology provides not only new collective action problems (e.g. control of cyber attacks), but also offers novel means for recognizing and addressing old collective action problems (e.g. monitoring the spread of pollutants and pests).

The primary purpose of this paper is to take stock of the current state of knowledge regarding collective action. To do so, the paper presents the basic propositions of collective action, contained in Logic. This is done briefly in Sect. 3, after some necessary preliminaries are given in Sect. 2. The remainder of the paper investigates the validity of these collective action propositions, which concern group size (Sects. 4, 5), group composition (Sect. 6), and institutional reform recommendations (Sect. 7). The paper identifies some key factors behind the validity of Olson's propositions, which include the form of the agents' utility functions, the nature of their cost functions, the purity of the public good, and the technology of aggregation (i.e. how individual contributions affect collective supply). Other considerations address the underlying strategic assumption and temporal factors. In terms of strategic aspects, a heavy emphasis is placed on the underlying games and their representations. Understandably, this paper must be selective in this regard, since it is not meant to be an exhaustive survey of the study of collective action. ${ }^{4}$ Section 8 indicates some modern-day applications of collective action in order to highlight Logic's continued relevance. Concluding remarks are contained in Sect. 9.

\section{Preliminaries}

A key topic of collective action concerns the provision of public goods by two or more providers. At the time of Logic, the classes of public goods corresponded to those based on two dimensions of publicness-benefit rivalry and nonexcludability. For nonrival benefits, a unit of the good can be consumed by one individual without detracting, in the least, from the consumption opportunities still available to others from the same unit. For example, one person's consumption of cleaner air does not detract from the improved air quality available to others. Such nonrival benefits result in a market failure because the good's

\footnotetext{
3 To gain an appreciation of this claim, see updated propositions in Sandler (1992, pp. 194-198). For example, an update to Olson's (1965) group size and suboptimality proposition might read as follows: With identical individuals and symmetric equilibriums, an increase in group size worsens suboptimality when a summation technology applies and the cost per unit exceeds the benefit per unit.

4 Thus, the paper does not examine dynamic issues or the role of uncertainty, except tangentially.
} 
implied zero marginal cost of consumption means that any charges for the good's use would result in suboptimality. This follows because some people deriving benefits are excluded by these charges even though their consumption is costless to society. If no private way of financing the good is possible, then public provision is needed. The second property of public goods is nonexcludability of benefits. Once provided, a good with nonexcludable benefits can be consumed by purchasers and nonpurchasers alike, thereby leading to free-riding incentives. Both publicness properties can result in suboptimal provision or market failure as resources are not channeled to their most valued use. Collective action failure can result because, without a means to finance the good, it may not be provided. Even if provided, free-rider incentives imply that a suboptimal level of the good is supplied as providers do not account for the benefits that their provision confers on others. ${ }^{5}$ For example, deterrence provided by an alliance's military arsenal offers nonrival and nonexcludable benefits to all allies if the promised threat of retaliation is credible (Olson and Zeckhauser 1966).

When a public good's benefits display some rivalry and/or excludability, it is an impure public good. Important classes of such goods include club goods, whose benefits are partly rival owing to a user-induced reduction in the quantity or quality of the good, known as congestion or crowding (Buchanan 1965; Sandler and Tschirhart 1980, 1997). Thus, extending access to the good to additional consumers is not costless, so that a toll, based on the marginal congestion cost of use, can foster optimal provision (Buchanan 1965; Sandler 2013). The rudiments of club analysis can be found in Olson's Logic under the notion of exclusive groups whose memberships must be restricted. Another important case of impure public goods is that of nonexcludable goods with partly rival benefits. Such goods may result in a collective action failure as an increase in group size reduces total and per person benefits, thereby inhibiting provision (Chamberlin 1974; Pecorino 2015).

During the last three decades, a third property of public goods, known as the technology of aggregation (or aggregation technology) is recognized to influence collective action (see, e.g. Cornes 1993; Cornes and Sandler 1984; Hirshleifer 1983; Sandler 1997; Vicary 1990). This third property indicates how individual contributions to the collective good determine the overall quantity of the good that is available for consumption. In Logic, the standard summation aggregator is assumed implicitly, such that a contributed unit adds equally to the aggregate provision of the collective good. As such, individual contributions are perfectly substitutable for those of other contributors, thereby bolstering free-riding incentives. Three particular aggregation technologies figure prominently in subsequent discussions. For a weakest-link public good, the smallest individual contribution fixes the overall provision of a public good (Hirshleifer 1983). A quarantine against a contagious disease abides by a weakest-link aggregator because the smallest or least-effective quarantine determines whether the disease spreads to infect others. Quarantine efforts beyond the minimum do not provide any additional protection. For a weakest-link public good, no incentive to free ride emerges, because doing so effectively brings overall provision down to zero. The weakestlink aggregator bolsters collective action by removing free riding as a desirable strategy, but it inhibits collective action by giving each potential contributor a possible spoiler role as a noncontributor. The latter is particularly worrisome for situations wherein some potential contributors do not have the means to contribute (Sandler 2015; Vicary and Sandler 2002).

A best-shot aggregator is also important for cases in which the largest effort determines the overall quantity of the collective good. Best-shot public goods include R \& D advances,

\footnotetext{
5 See standard treatments of public goods and market failures, such as Boadway and Bruce (1984) and Cornes and Sandler (1996).
} 
assassinating a notorious terrorist, gaining intelligence, or finding a cure to a disease. For best-shot public goods, efforts and resources must be channeled to the potential provider who is most apt to succeed. Consequently, coordination is needed to achieve provision and to avoid wasteful duplicate efforts. This coordination constitutes the required collective action. A third aggregator is threshold, such that provision of the public good must surpass some baseline level before benefits accrue to the group (Bagnoli and McKee 1991; Dixit and Olson 2000; Palfrey and Rosenthal 1984; Sandler 1992). For example, fire suppression efforts must exceed some threshold before any containment is achieved.

Another important preliminary consideration is Olson's (1965) notion of a privileged group. The idea refers to at least one individual or coalition whose perceived benefits from collective action exceed the associated costs, even if these costs are borne solely by the individual or coalition. If a group is privileged, then some subgroup of actors provides the collective action that furthers everyone's well-being. For instance, the US Centers for Disease Control (CDC) monitors disease outbreaks and isolates new microbes globally as a way of protecting US citizens. The United States funds the CDC independently even though its efforts protect people worldwide. At the start of the Cold War, the US nuclear arsenal protected or privileged Western Europe by deterring further Soviet expansion. Open domain software is a best-shot public good whose users are privileged by the program's developer.

Since much of the paper's arguments are based on game theory, two essential gametheoretic notions must be introduced. Nash behavior involves each player acting independently or in isolation. A Nash equilibrium corresponds to each player choosing its best response in reaction to the best response(s) of the other player(s). At a Nash equilibrium, no player unilaterally will change its strategy since it has chosen a best response. Games may possess many Nash equilibriums, but some may be more desirable than others. Collective action difficulties may be associated with a variety of game forms, not just the familiar Prisoners' Dilemma. Another important game-theoretic concept is that of a dominant strategy that gives a player a larger payoff regardless of the other players' strategies.

\section{General rules of thumb for collective action}

Table 1 draws nine propositions from Olson's (1965) Logic, which are displayed under three subgroupings - size of group, group composition, and institutional recommendations.

Table 1 Collective action: general rules of thumb

Size of group

Large groups may not form to provide themselves with the collective good (strong version)

The larger the group, the smaller the collective provision level (strong version)

The larger the group, the greater the inefficiency associated with individual uncoordinated/Nash behavior (weak version)

Group composition

Larger members with greater endowments bear a disproportionate burden of collective provision (action) (exploitation hypothesis)

Heterogeneous groups are more apt to achieve some collective action

Homogeneous groups are more apt to form

Institutional recommendations

Collective action is promoted by selective incentives that bolster individual gains

Collective action may be fostered by institutional design — for example, refunds or federated structure 
Pecorino (2015) characterized the first two propositions as the strong versions of the influence of group size on collective action: large groups may not form or be privileged, and larger groups are characterized by smaller collective provision. The weak form of the group size proposition indicates that collective provision is more suboptimal for larger groups. Olson also advanced three maxims with respect to group composition. The celebrated exploitation hypothesis says that large (better-endowed) members shoulder a disportionately heavy burden of collective provision for the small members. ${ }^{6}$ This hypothesis held for NATO allies until 1964 (Olson and Zeckhauser 1966). The last two composition propositions concern group formation. Potential collectives with members who possess different tastes and/or endowments are more apt to provide some collective action, primarily because such differences are apt to result in a privileged group. In addition, homogeneous collectives are more likely to form owing to minimal participation costs. Reaching decisions on collective action is less costly when members have similar means and preferences.

Olson (1965) also offered some institutional recommendations. Selective incentives that reward providers with private gains foster collective action by raising contributors' perceived benefits. Moreover, institutions that make individuals' actions more noticeable to the group will promote collective action. This is particularly true of federated structures, such as those used by labor unions (Olson 1965), wherein much of the collective action is conducted at the local level. At this level, the interacting group is small and individual contributions are noticed. Other institutional principles were indicated by Olson (1965) and extended by Ostrom (1990), Schotter (2008), and others.

\section{Group size propositions}

Olson's (1965) Logic did not offer a clear model from which his group size maxims followed (Ostrom 1987; Sandler 1992). In particular, the forms of the participants' utility and cost functions never were specified (Esteban and Ray 2001; Pecorino and Temimi 2008). Moreover, Olson appeared to have in mind a collective good whose benefits are rivalrous. Olson's first group size proposition stemmed from his notion that an increase in the size of the entire collective reduces any subgroup's share of the group's benefits from collective action (Olson 1965, pp. 33-34, 48). ${ }^{7}$ This result, however, requires that the collective good possesses rivalrous benefits. For a pure public good, any subgroup's derived benefits are independent of the size of the collective. That is, the subgroup's benefit equals $n M R S_{G y}$, where $n$ is the subgroup's size and $M R S_{G y}$ is an individual's marginal rate of substitution $(M R S)$ between the public good $(G)$ and a private numeraire good $(y)$. The subgroup's aggregate benefit is invariant to the size of the entire collective when no benefit rivalry is present. If, however, crowding is implied, then the subgroup's benefit must be weighted by some marginal crowding term, which reduces the subgroup's gains as the collective grows in size. In so doing, crowding reduces the likelihood that a subgroup derives sufficient gains to privilege the entire collective as the latter grows in size, which is in keeping with Olson's first size maxim.

The second group size proposition is invalid for purely public goods when tastes display normal income elasticities for the private and public goods (Chamberlin 1974; McGuire

\footnotetext{
6 The notion of large is never clear in Logic. It may refer to endowments or to population (Vicary 2009).

7 Sandler (1992, pp. 23-27) offered a stylized model for Olson's analysis based on some of Olson's notation and definitions.
} 
1974). For homogeneous contributors, Chamberlin (1974) showed that the overall contribution to the public good increases to a finite limit as group size increases even though per person contributions decline. This per person reduction is more than offset by contributions from the new members as group size expands, provided the collective good is income normal. If, however, the collective good is inferior and/or rival, then Olson's second group size maxim may hold.

Subsequently, the private provision of public good analysis supported Chamberlin's and McGuire's view of the second maxim (Andreoni 1988; Bergstrom et al. 1986; Cornes and Sandler 1984). For this analysis, individual $i$ maximizes utility, $U_{i}$, which depends on a private good, $y_{i}$, and a pure public good, $G$. The latter is the sum of the individual $i$ 's contribution to the public good, $g_{i}$, and the amount contributed by others, $G_{-i}=\sum_{j \neq i}^{n} g_{j}$, so that $G=g_{i}+G_{-i}$. The individual's budget constraint is

$$
y_{i}+p g_{i}=w_{i}
$$

where the price of the private good is unity, the price of the public good is $p$, and individual $i$ 's income is $w_{i}$. Hence, each individual faces the following problem,

$$
\max _{y_{i}, g_{i}}\left\{U_{i}\left(y_{i}, g_{i}+G_{-i}\right) \mid y_{i}+p g_{i}=w_{i}\right\},
$$

where $G_{-i}$ is treated as a constant owing to the assumed Nash behavior. The associated first-order conditions (FOCs) include the budget constraint in (1) and

$$
M R S_{G y}^{i}=p .
$$

Equation (3) indicates that each contributor equates his or her marginal benefit from the public good to the relative price of the public good, thereby ignoring the benefits that his or her contribution confers on others. This then implies suboptimality because optimality from the group's perspective requires that

$$
\sum_{i=1}^{n} M R S_{G y}^{i}=p
$$

is satisfied. Thus, the private provision of a public good model supports Olson's suboptimality concern. This model provides a foundation for the third group size maxim because benefits ignored in (3) correspond to $\sum_{j \neq i}^{n} M R S_{G y}^{j}$, which grows with group size.

I next consider stylized representations of the public good contribution and commons games to analyze Olson's size propositions further. In Fig. 1a, five identical persons can contribute one or no units of a pure public good at a per unit cost, $c_{i}$, of 8 . Each contributed unit gives all five persons a benefit, $b_{i}$, of 5 . If individual $i$ does not contribute, then $i$ receives 0 when no one else contributes. If, however, one person other than $i$ contributes, $i$ gains 5 . When two others privilege $i$ with a free ride, then $i$ gains 10 . The other payoffs in the top row are computed in a similar manner. If individual $i$ contributes alone, then $i$ nets -3 , which equals $b_{i}-c_{i}$. When $i$ 's contribution is matched by two other contributors, then $i$ gains $3 b_{i}-c_{i}=15-8=7$. The other payoffs in the bottom row of Fig. 1a are calculated in an analogous fashion. Notice that a summation aggregator applies, insofar as benefits are multiplied by the number of contributors. 


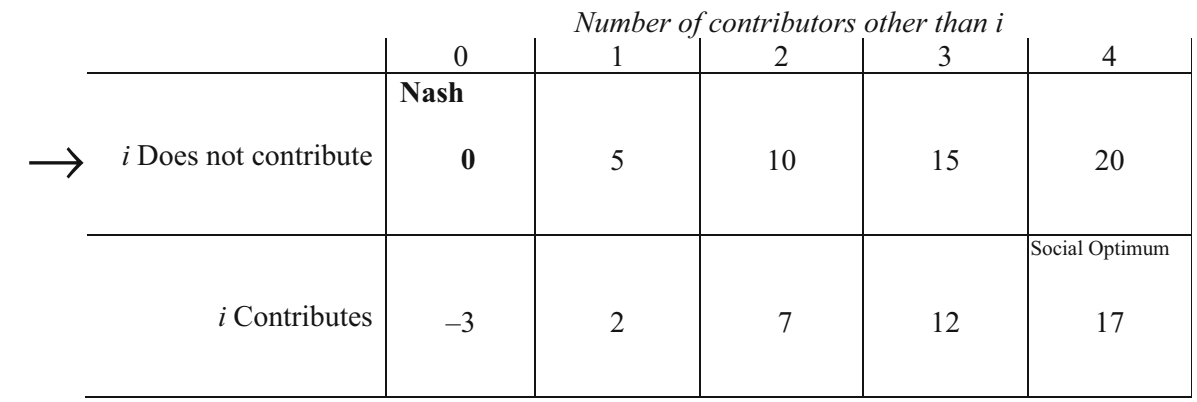

a Five-person contribution game, $b_{i}=5, c_{i}=8$

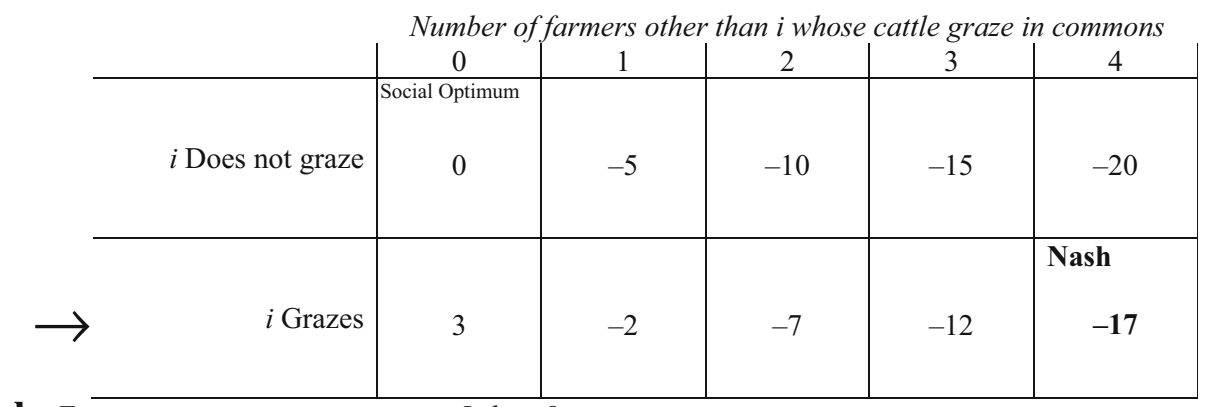

b Five-person commons game, $c_{i}=5, b_{i}=8$

Fig. 1 Five-person symmetric representations for contribution and commons games

The dominant strategy for the game in Fig. 1a is not to contribute since every payoff in the top row is 3 greater than the corresponding payoffs in the bottom row. As individual $i$ and the four other individuals play their dominant strategies, the Nash equilibrium emerges in which no one contributes. At this equilibrium, neither $i$ nor any of the other individuals unilaterally will change their strategies, given that $0>-3$. The social optimum requires everyone to contribute for an aggregate payoff of $85(=5 \times 17)$, which also represents the amount of suboptimality associated with the Nash equilibrium, whose aggregate payoff is 0 . The resulting game is a Prisoners' Dilemma (PD).

In Fig. 1b, an analogous open-access commons game is displayed, where now $b_{i}=8$ and $c_{i}=5$. If $i$ refrains from grazing his or her cattle, then $i$ 's payoff is -5 times the number of ranchers using the commons. By exploiting the commons, a rancher imposes public costs on others in return for a private benefit. This is the opposite of the contribution game wherein the benefits are public and the costs are private (Sandler and Arce 2003). When just rancher $i$ grazes his or her cattle on the commons, $i$ nets 3 as costs of 5 are deducted from $i$ 's benefits of 8 . When $i$ and one other rancher exploit the commons, then each receives $-2(=8-2 \times 5)$. The other payoffs follow in a similar fashion. The dominant strategy in this PD game is for all five ranchers to graze their cattle on the commons, thus resulting in per rancher losses of 17 for an aggregate loss of 85 . Despite this loss, $i$ will not unilaterally switch to not grazing because $-17>-20$.

For the contribution game, there is no action; for the commons game, there is too much action (Sandler and Arce 2003). In both cases, the desirable collective action fails to emerge, and the extent of suboptimality increases with the size of the group, thereby illustrating Olson's first and third group size propositions. A summation aggregator, in 
Fig. $2 N$-person contribution game

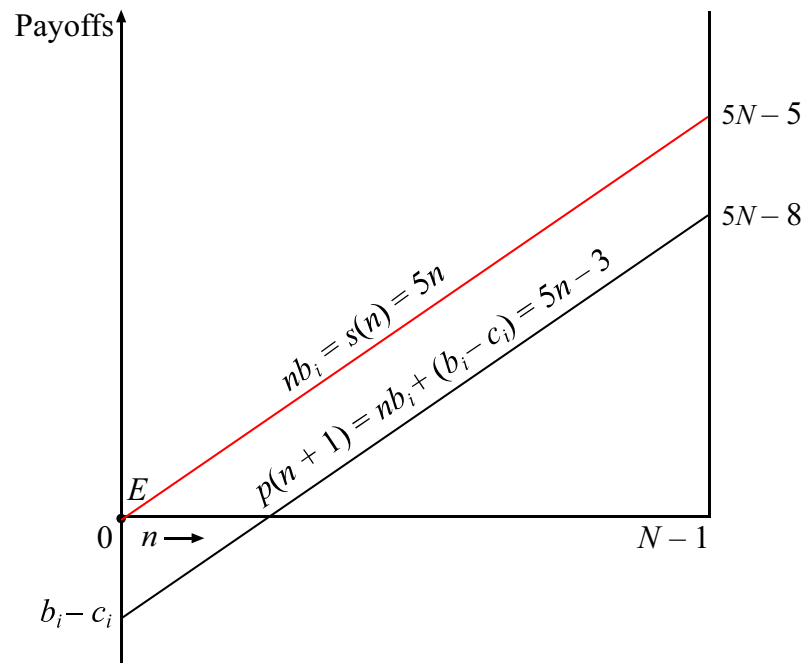

terms of benefits for the contribution game and in terms of costs for the commons game, underlies these two canonical representations. In addition, Nash behavior is assumed.

Next I extend both games to $N$ players. In Fig. 2, payoffs are measured on the vertical axes, while the number of other contributors, $n$, is displayed on the horizontal axis. Two linear functions, based on the previous contribution game, are depicted. The participation payoff is denoted by $p(n+1)$ and the shirking payoff is denoted by $s(n) .{ }^{8}$ The participation payoff corresponds to being a contributor when $n$ others contribute. For $p(1), n=0$ and the representative player contributes alone for a net gain of $b_{i}-c_{i}=-3$. For $N-1$ other contributors, player $i$ gains $(N-1) b_{i}+\left(b_{i}-c_{i}\right)=5 N-8$ when contributing, as displayed on the right-hand vertical axis. In-between payoffs for the participation relationship are computed in a similar fashion for different values of $n$. Shirking gives the representative player a payoff of 5 times the number of contributors or $s(n)=5 n$, which has a maximum value of $5 N-5$ when all but $i$ contributes. Player $i$ shirks because $s(n)>p(n+1)$ for all values of $n$, leading to a Nash equilibrium at $E$, where no collective action is undertaken. The extent of suboptimality equals $N(5 N-8)$, which increases with group size, thereby confirming Olson's third group size proposition.

The five-person commons game is now extended to its $N$-person analogue in Fig. 3. For $b_{i}=8$ and $c_{i}=5$, the participation payoff equals $3-5 n$, while the shirking payoff equals $-5 n$. The left vertical intercept for the participation function is $b_{i}-c_{i}=3$, while this intercept for the shirking function is 0 . In contrast to the contribution game, both functions are downward sloping and the participation payoffs exceed the corresponding payoffs for shirking (i.e. not exploiting the commons) for all levels of $n$. The Nash equilibrium is at point $E$, at which everyone exploits the commons to the detriment of the collective welfare. This result is known as the "tragedy of the commons" (Hardin 1968). As group size increases, the extent of suboptimality also increases and equals $-5 N+8$ times $N$, since each member loses $-5 N+8$. Olson's third group size proposition holds for an open-access commons. Figures 2 and 3 display the dual nature of the contribution and commons games in their purest forms (Sandler and Arce 2003), so that the relative positions and orientation of the participation and shirking functions are switched. This switch results in too little

\footnotetext{
8 These payoff functions are discussed in Dixit et al. (2009).
} 


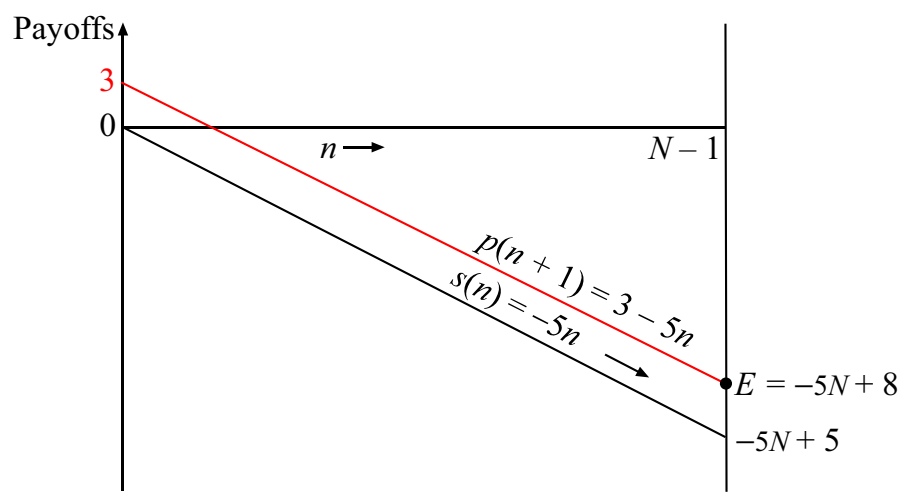

Fig. $3 N$-person commons game

action in the contribution game and too much action in the commons. In the latter case, the group forms too easily. This duality of the two games is shown later to reverse the exploitation hypothesis.

\section{Influence of other aggregation technologies on group size}

In 1965, summation was the only aggregation technology assumed. We now know that other aggregators do not necessarily support Olson's size maxims. Consider a weakest-link public good, such that the smallest contribution level determines the overall provision level. If everyone is identical in terms of tastes and income, then everyone will desire the same level of provision and will match one another's contributions to the collective good. It is as though each individual faces the social-optimizing problem. The resulting Nash equilibrium is the social optimum, so that Olson's third maxim for group size does not hold-i.e. an increase in group size does not worsen suboptimality for weakest-link collective goods for homogeneous individuals (Mueller 2003, pp. 22-25; Sandler 1992, pp. 52-53). ${ }^{9}$ Harrison and Hirshleifer (1989) confirmed this result in an experimental setting. If, however, some individuals have lower incomes, then they may not be able to afford the social-optimizing provision point and need help in terms of "shoring up" by others (Vicary and Sandler 2002). With unequal incomes, suboptimality may arise for weakest-link public goods, because shoring up implies a PD game, wherein rich countries attempt to free ride on the shoring-up efforts of other rich countries (Sandler 2015).

Next consider a best-shot public good such that the largest contribution fixes the aggregate provision level. Best-shot public goods weaken Olson's first group size principle in the case of unequal incomes. In this scenario, a rich contributor with strong preferences for the good may privilege everyone regardless of group size. If US-sponsored effort by GlaxoSmithKline to develop a vaccine for Ebola succeeds, then all countries or people will benefit. The number of countries in need of the vaccine does not affect the discovery of the vaccine. This is also true for efforts to isolate new microbes. The size of the group does not necessarily inhibit the likelihood of being privileged, which instead depends on having a sufficiently well-endowed provider. In fact, larger groups are more apt to contain such a

\footnotetext{
9 At the Nash equilibrium, each contributor satisfies $M R S_{G y}^{i}=p$. No free-rider benefits are available, thereby requiring everyone to achieve this equality at the social-optimizing public good level.
} 


\begin{tabular}{r|c|c|c|c|c|} 
& \multicolumn{6}{|c|}{ Number of contributors other than $i$} \\
\hline & Nash & 1 & 2 & 3 & 4 \\
\hline Does not contribute & $\mathbf{0}$ & -1 & -2 & 9 & 12 \\
& & & & & \\
\hline Contributes & -1 & -2 & 9 & 12 & $\mathbf{1 5}$ \\
\hline
\end{tabular}

Five-person contribution game, $b_{i}=4$ after threshold of 3 contributors, $c_{i}=5 n / N$

Fig. 4 Five-person assurance game

contributor, which is why best-shot public goods may have a more difficult time being supplied at the local or regional level than at the global level.

As a final aggregator, I consider a discrete threshold public good, for which benefits begin to accrue to group members only after a predetermined quantity of the good is provided (Bagnoli and McKee 1991; Palfrey and Rosenthal 1984; Dixit and Olson 2000). Suppose that benefits of 4 per contributed unit are received by each individual only after, say, three units are contributed. The underlying game is initially assumed to have five potential contributors, each of whom may contribute one or no units at a per unit cost of 5 . In this game, a cost-sharing structure also is assumed, wherein each of the five individuals covers one-fifth of the cost per unit, no matter who provides the units. If there are, say, four contributors $(n=4)$, then each group member pays $(5 \times 4) / 5=4$ in costs. The same also is true for noncontributors.

The normal-form threshold game is depicted in Fig. 4. When the number of contributors is below the threshold, each member pays $-n$ in costs. In the top row, noncontributor $i$ must pay -1 and -2 when one or two others have contributed, respectively. Next consider the case where the threshold is just met. In the bottom row, this occurs when $i$ and two others contribute, so that $i$ nets $9[=(3 \times 4)-3]$. If $i$ and three others contribute, then $i$ gains $12[=(4 \times 4)-4]$. The other payoffs are computed similarly. Two Nash equilibriums exist for this assurance game, namely no one or everyone contributes (Runge 1984; Sandler 1992). At these two equilibriums, $i$ will not want to alter its strategy unilaterally. If each individual in this game can be assured that the threshold is met, then each will want to contribute. ${ }^{10}$ The full-participation Nash equilibrium is also the social optimum where aggregate benefits are 75 .

Figure 5 generalizes the game to $N$ players with the same benefits per contributed unit, cost per unit, threshold, and cost-sharing arrangement as in Fig. 4. Once the three-contributor threshold is attained, the participation and shirking functions switch their relative positions so that the participation payoff exceeds that of shirking. In consequence, the Nash equilibrium is at $E=3 N$. Below this threshold, the shirking payoff exceeds that of participation, leading to a Nash equilibrium at $E_{2}=0$. A hallmark of assurance games is multiple equilibriums that include both action and no action. The cost-sharing arrangement means that the action equilibrium is a social optimum. Thus, this assurance game violates the third group size maxim, because an increase in group size does not necessarily imply

${ }^{10}$ If costs are not shared, then the resulting assurance game has 11 Nash equilibriums - the number of ways that groups of 3 can be drawn from a group of 5 plus the zero contribution equilibrium (Palfrey and Rosenthal 1984; Sandler 1992). 


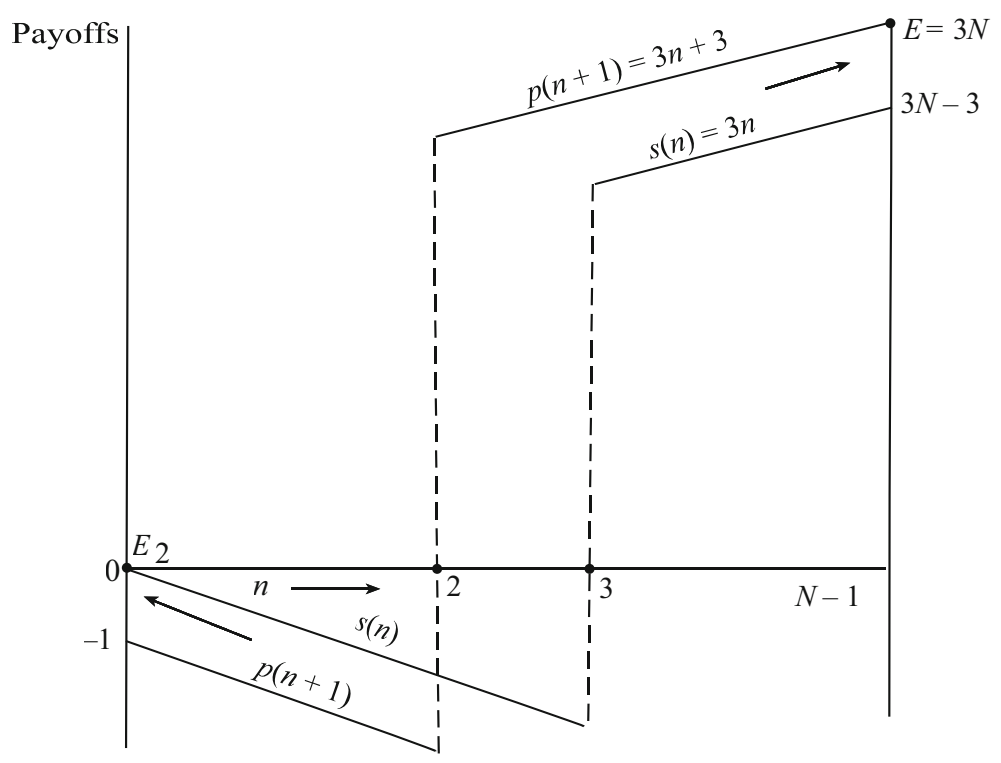

Fig. $5 \mathrm{~N}$-person assurance (threshold) game

greater suboptimality. In fact, as $N$ becomes infinitely large, the participation payoff becomes more attractive relative to shirking since, prior to reaching the threshold, one's share of the cost approaches zero. This assurance game also speaks against the first group size maxim - the possibility of group formation or being privileged is not necessarily inhibited by group size because of cost sharing.

\section{Group composition}

Olson's three group composition maxims are now considered.

\subsection{Exploitation hypothesis}

I focus on the exploitation hypothesis because recent interesting surveys of Logic have little to say about this important maxim wherein the large is exploited by the small. There are many situations where this maxim is not true. To accomplish my purpose, I must return to the private provision of pure public good model, which is now presented in its fullincome representation as

$$
\max _{G}\left\{U_{i}\left(y_{i}, G\right) \mid y_{i}+p G=w_{i}+p G_{-i}\right\} .
$$

In (5), $p G_{-i}$ (the value of spillovers) has been added to both sides of the budget constraint in (1) and $G$ replaces $g_{i}+G_{-i}$. For a strictly increasing quasi-concave utility function and income normal goods, the associated Nash demand for the aggregate public good is 


$$
G=\max \left\{f_{i}\left(w_{i}+p G_{-i}, p\right), G_{-i}\right\},
$$

where $G=G_{-i}$ if $i$ is a noncontributor (Andreoni 1988; Bergstrom et al. 1986; Sandler and Posnett 1991). For contributors, the demand for the public good, $G^{*}$, at a Nash equilibrium is

$$
G^{*}=f_{i}\left(w_{i}+p G_{-i}, p\right),
$$

where $\partial f_{i} / \partial\left(w_{i}+p G_{-i}\right)$ lies between 0 and 1 owing to the assumed income normality of the public good. Based on (7), contributor $i$ 's demand is ${ }^{11}$

$$
g_{i}=\left[w_{i}-w^{*}(p)\right] / p,
$$

where $w^{*}(p)$ is the cutoff income for being a contributor, so that $i$ contributes only when $w_{i}>w^{*}(p)$. Thus, only the richest group members contribute when tastes are identical but incomes differ (Andreoni 1988; Andreoni and McGuire 1993; Bergstrom et al. 1986). This representation supports the exploitation hypothesis for identical tastes, pure public goods, income normal goods, and Nash behavior.

A simple refutation of the exploitation hypothesis follows if tastes for the public good runs counter to income so that the poorer group members have the most interest in the public good. Consider the Israeli-United States military alliance. Israel has a much greater preference for its own defense in the Middle East where it has many enemies. As a consequence, Israel typically spends a larger percentage of its gross domestic product (GDP) on defense than its richer and larger ally, the United States.

The validity of the exploitation hypothesis may hinge on the underlying strategic assumption in the case of a collective good. This can be established by reconsidering the private provision of public good model under Nash and leader-follower assumptions. To do so, I return to Eq. (2) and substitute the budget constraint into the utility function to give

$$
U_{i}\left(w_{i}-p g_{i}, g_{i}+G_{-i}\right)=U_{i}\left(g_{i}, G_{-i} ; p, w_{i}\right),
$$

which depicts utility in terms of $g_{i}, G_{-i}$ (spillovers), and the fixed parameters of price and income. If the game involves just two individuals, $i=1,2$, then (9) becomes

$$
U_{1}\left(g_{1}, g_{2} ; p, w_{1}\right)
$$

with a similar income-constrained utility function for individual 2 in terms of $g_{1}, g_{2}, p$, and $w_{2}$. The representation in (10) implies an iso-utility contour with slope

$$
\frac{d g_{2}}{d g_{1}}=-1+\frac{p}{M R S_{G y}^{1}}
$$

by the implicit function rule. These contours can be displayed in $\left(g_{1}, g_{2}\right)$ space for given price and incomes.

In Fig. 6, we display two of individual 1's income-constrained, iso-utility contours, II and $I^{\prime} I^{\prime}$. For individual 1 , each such contour is U-shape and achieves a minimum, ${ }^{12}$ where $M R S_{G y}^{1}=p$ for a given level of $g_{2}$. The reaction path, $R_{1}$, in Fig. 6 connects these minimums and represents individual 1's best response for each $g_{2}$ level (Sandler 1992). Individual 2's income-constrained, iso-utility contours have their minimums oriented to the

\footnotetext{
11 This follows by taking the inverse of both sides of (7) and by adding $p g_{i}^{*}$ to both sides. This then gives $f_{i}^{-1}\left(G^{*}, p\right)-p G^{*}=w_{i}-p g_{i}^{*}$. Finally, let $w^{*}(p)$ equal the left-hand side and solve for $g_{i}^{*}$.

12 At this minimum, $d g_{2} / d g_{1}=0$, so that the stated equality follows.
} 


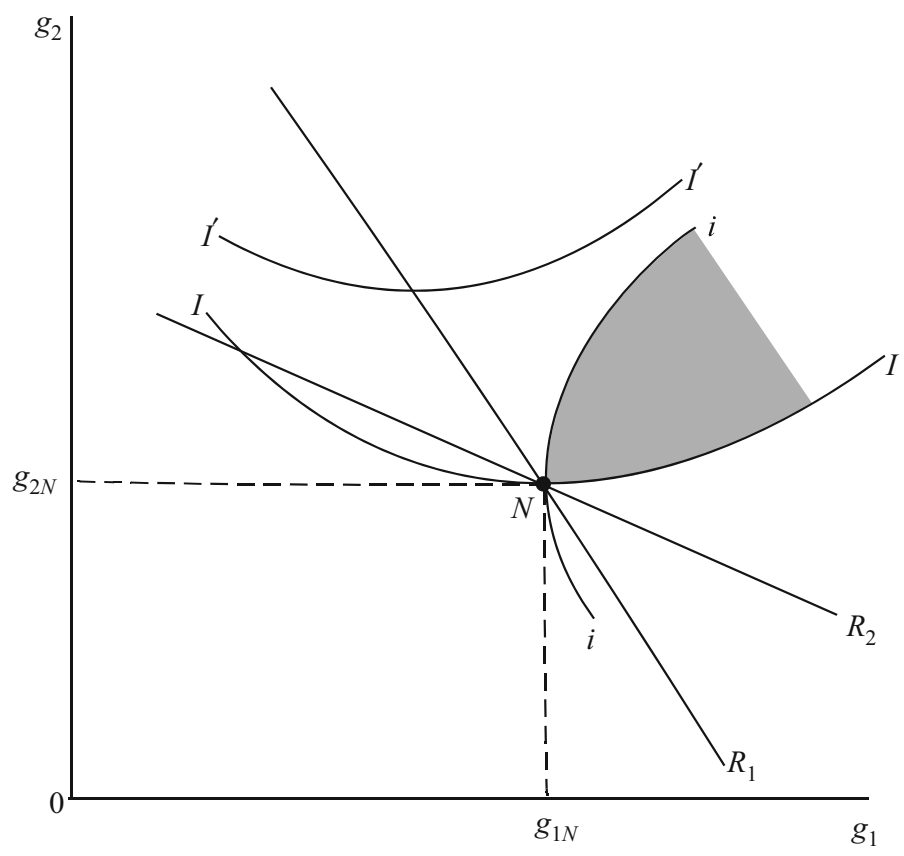

Fig. 6 Two-agent Nash contributor equilibrium

vertical axis as shown by curve $i i$ in Fig. 6. Connecting these best-response points gives individual 2's reaction path $R_{2}$. The intersection of these reaction paths is the Nash equilibrium, $N$, where individual 2 contributes $g_{2 N}$ and individual 1 contributes $g_{1 N}$. The shaded lens-shaped region between the Nash equilibrium's iso-utility contours for the two individuals indicates the Pareto-improvement area wherein both individuals are better off (i.e. achieve more utility) than at the Nash equilibrium. Even in the case of two individuals and a summation aggregator, the Nash outcome is suboptimal.

In Fig. 7, the Nash equilibrium for a large agent $L$ and a small agent $F$ is indicated at $N$, where the reaction paths intersect. It is easy to see that individual $F$ contributes far less than individual $L$ at this equilibrium. Increases in $L$ 's income would shift $L$ 's reaction path to the right (not shown), making for even greater inequity of burden sharing. The total contribution at $N$ is found by extending a line with slope -1 to the horizontal axis, giving $G^{N}$ as this total. Next suppose that individual $L$ is a leader and individual $F$ is a follower. The follower takes the leader's contribution as given, thereby behaving no differently than for the Nash representation. As such, $R^{F}$ represents $F$ 's follower reaction path. The leader, however, chooses its best iso-utility contour using $R^{F}$ as a constraint; hence, $L$ picks point $S$ in Fig. 7 where its iso-utility contour is tangent to $F$ 's reaction path. As a result, $L$ 's welfare improves and $F$ 's welfare worsens compared to their respective iso-utility contours through $N$. At this leader-follower equilibrium, the leader strategically shifts more of the burden onto the follower and may reverse the exploitation. ${ }^{13}$ This stems from the leader anticipating the follower's larger contributions as the leader reduces its contributions. The

13 A corner solution is also possible with the follower providing all of the public good (Cornes and Sandler 1996, pp. 331-333). 


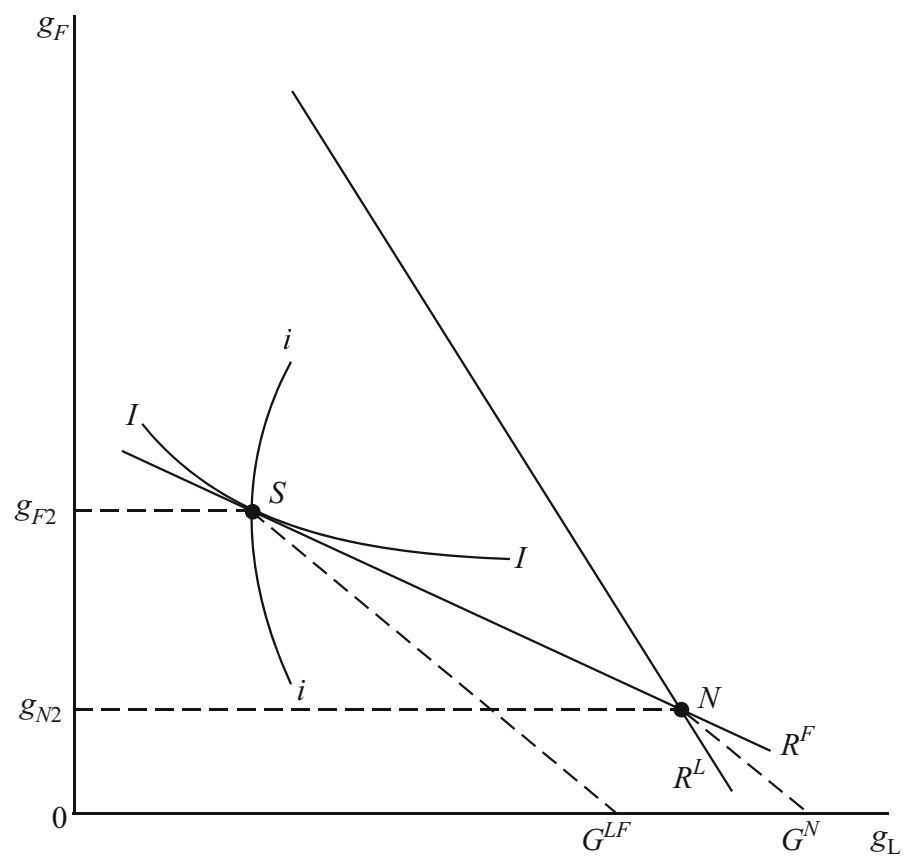

Fig. 7 Leader-follower behavior and reversed exploitation

overall public good level falls from $G^{N}$ to $G^{L F}$ owing to the leader's strategic behavior. The important point is that alternatives to Nash behavior may reverse exploitation.

When Olson (1965) put forward his exploitation hypothesis, he had a collective good and not a commons in mind. In a commons, the exploitation hypothesis is often reversed with the small shouldering the crowding burden of the large (Sandler and Arce 2003; Vicary 2009). Consider the normal-form game in Fig. 8 for two exploiters of a fisherysmall firm $A$ with 5 vessels and large firm $B$ with 10 vessels. Suppose that each vessel imposes a public crowding cost of 5 and earns a gain of 8 per vessel for the firm. Based on these costs and benefits, the payoffs in Fig. 8 follow for this PD. At the Nash equilibrium the small firm loses heavily, while the large firm just makes a profit. Clearly, the small firm shoulders the greater burden owing to other-generated crowding. In fact, this reversed exploitation often holds for any congestion situation-e.g. two trucking firms sharing a free highway.

\subsection{Other group composition principles}

Olson (1965) was optimistic that heterogeneous groups would achieve some collective action as a rich individual privileges the rest of the group. This is clearly the case for the private provision of a pure public good for homogeneous tastes, different incomes, Nash behavior, and summation aggregation. For this scenario, Bergstrom et al. (1986) showed that the richest individuals provide the public good. If, however, a weakest-link public good is to be provided, then the richest individual must bring everyone's contribution level to some minimum quantity. This may require huge shoring-up commitment in a large 
Fig. 8 Reversed exploitation in a commons

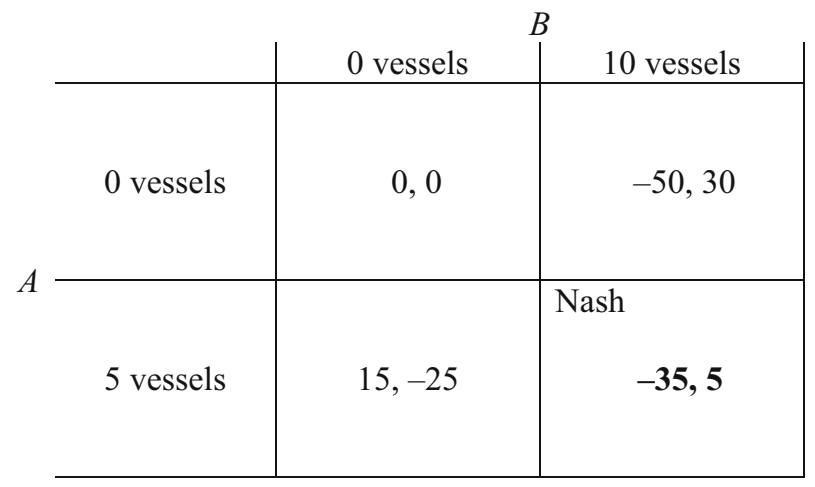

group with many poor individuals. In a recent article, Sandler (2015) established that this may, at times, pose an insurmountable problem. Difficulties may be compounded among capable contributors as they attempt to free ride on the largess of other capable contributors, thereby leading to a PD. This worrisome scenario may apply to a quarantine against a deadly disease that is indigenous to many poor countries. Consider what the 2014 Ebola outbreak would have been like if it had spread to all of Africa. Rich countries would have needed to contain the disease throughout the continent, which would have taxed their capabilities greatly. Coordination problems and the lack of healthcare workers posed significant worries when Ebola was confined to a few Western African countries.

Another issue for Olson's heterogeneous composition provision maxim involves benefit rivalry or crowding. With sufficient crowding, large groups may not provide any of the collective good, because the benefits per person are too small (Pecorino and Temimi 2008). This may even be true for the richest individual for very large groups as crowding discounts this individual's benefits so that costs cannot be covered profitably. Esteban and Ray (2001) and Pecorino and Temimi (2008) also showed the relative importance of nonlinear costs and the crowding parameter for Olson's group size maxims. Suffice it to say that crowding has a role to play for many of Olson's principles of collective action.

Olson's final group composition maxim concerns the greater likelihood of homogeneous groups forming. This maxim assumes implicitly that identical tastes and income curtail participation costs. Dixit and Olson (2000) indicated that participation costs may be a real concern for threshold public goods, wherein the right number of participants is required. Dixit and Olson (2000) modeled the collective decision in two stages: stage 1 requires individuals to decide to participate or not, while stage 2 involves bargaining over the provision level. ${ }^{14}$ These authors showed that the likelihood of provision is extremely low for large groups when the participation threshold is less than the group's size. This probability virtually goes to zero in the presence of participation costs. Olson himself was not sanguine about his homogeneous composition principle for a threshold aggregator and participation costs.

Other aggregation technologies may play havoc with this maxim. Consider a best-shot scenario wherein homogeneity means that no one is willing to provide the best-shot public good, because no group members are better endowed than others. This is a concern for

${ }^{14}$ Dixit and Olson (2000) specifically related their exercise to Coasian bargaining to internalize an externality. 
some regions of Africa or Asia when an extraordinary provision effort is required by an indigenous country to confront a public health or other emergency.

Finally, imperfect information may work against this maxim for assurance games when participants must be convinced that the right number of others will come forward. This poses an information problem even for homogeneous group members, which is particularly acute when a large number of participants are needed (Sandler 2015).

\section{Institutional recommendations}

Olson (1965) also offered institutional recommendations for addressing collective action failures. He realized that private inducements or selective incentives may encourage collective action. Consider the act of overthrowing a ruthless dictator, who would exact horrible retribution on anyone who opposes his rule (Tullock 1974). Volunteers may still come forward, driven, in part, by the anticipated glory or power after the ruler is deposed. These volunteer-specific benefits are selective incentives that may bolster collective action by making the volunteer's perceived benefits outweigh the costs. Even a suicide terrorist may be induced to make the ultimate sacrifice for the collective's well-being owing to selective incentives (e.g. martyrdom, family rewards, and camaraderie). Cornes and Sandler $(1994,1996)$ demonstrated that selective incentives are most effective when they are produced jointly with the public good and are complementary to it. The latter means that the benefits derived from the associated private good increase with the level of the jointly provided public good. For example, concert tickets, given to large contributors to the symphony, increase in value as the orchestra's quality improves, because of the enhanced support. Sufficient complementarity may result in positively sloped reaction paths (Cornes and Sandler 1994), so that individuals increase their contributions as others give more.

These selective incentives may be ineffective if they are perfect substitutes for the public good and can be purchased independently. In this case, strong incentives to free ride surface as individuals seek to purchase the selective private good on its own. Even when purchased together, reaction paths for the jointly produced activity are negatively sloped and some free riding occurs.

Olson (1965) viewed institutional design as a means for encouraging effective collective action. This message also formed the foundation of Ostrom's (1987, 1990) myriad contributions to the study of institutionally-promoted collective action. In Logic, federated structures were seen as a way to foster collective action in smaller local groups when those groups are part of a larger institution. Olson's work was instrumental in generating a literature on institutional design. The trick was to engineer cheap-to-operate institutions that altered incentives so that contributing was transformed into a dominant strategy (see, e.g. Bagnoli and McKee 1991; Hardin 1982; Libecap 2014; Libecap and Wiggins 1984; Ostrom 1990; Taylor 1987). For example, the standard PD game can often be addressed by cost sharing. ${ }^{15}$ The United Nations funds its peacekeeping operations since 11 December 1973 from assessment accounts, by which member countries share the costs of such missions (Solomon 2007). INTERPOL also is financed by cost shares imposed on member countries. Homeowner associations in gated communities and condominiums share costs for common grounds, infrastructure, and collectively consumed facilities. For threshold public goods, refunds prior to the threshold being reached can foster the attainment of the

15 This holds if $N>c_{i} / b_{i}$, where $N$ is the group size. 
threshold because contributors assume no risks if total contributions fall short (Bagnoli and McKee 1991; Sandler 2004).

Ostrom (2000) pushed the notion of evolving social norms as a means of curbing overuse of the shared commons. Based on insights gained from laboratory experiments and field studies, she viewed evolutionary game theory as fostering effective collective action. Individuals exercising effective strategies emerge, survive, and multiply.

Two obvious impediments can arise to the use of institutional engineering as a means for promoting more effective collective action. First, large transaction costs can wipe out the gained efficiency stemming from the institutional innovations. For clubs, the partly rival public good can be shared efficiently if use can be monitored finely and tolls charged accordingly. Moreover, the exclusion mechanism must be virtually costless to operate (Buchanan 1965; Sandler 2013). A costly mechanism may require coarse exclusion, in which a membership fee is assumed and not a per unit utilization charge (Helsley and Strange 1991). Coarse exclusion induces members to expand their use until their marginal benefit is zero, thereby resulting in too much crowding. Second, multiple stages of interaction may be required for some institutions, which may reduce efficiency. Dixit and Olson (2000) showed this to be the case of consummating a Coasian bargain for a threshold public good, wherein a participation decision stage preceded the bargaining stage.

\section{Myriad applications}

The study of collective action remains relevant with new applications arising daily. Space allows me only to highlight a few applications.

Many environmental challenges-climate change, ozone shield depletion, heavy metal pollutants, and acid rain-represent global and regional collective action problems. Climate change has proven particularly difficult to address, with developing countries demanding that developed countries reduce their greenhouse gases (GHGs) while poorer countries continue to grow their economies (Sandler 2004, 2015). Such countries as India and China want to be spared from curbing their GHG emissions on equity grounds-i.e. much of the GHGs accumulated in the atmosphere came from developed countries. The developing countries' demand poses a problem because these populous countries have the fastest growing carbon footprints. Until now, the achievement of environmental collective action relied on international treaties. For example, the Montreal Protocol on limiting ozone-depleting substances has been very successful, because the production and consumption of these substances were concentrated in relatively few countries, no country benefited from a thinner ozone layer, the science of ozone layer depletion was known, substitutes for ozone depleters were found, and restoring the ozone layer would take just four to five decades (Sandler 2004). The control of sulfur-based acid rain has been successful in Europe and elsewhere owing to effective abatement and the presence of monitoring stations.

The rise of transnational terrorism presents many collective action concerns of varying difficulty to solve (Sandler 2005). The elimination of terrorist safe havens has proven especially difficult because even one or two safe-haven countries can annihilate the efforts of other countries. Failed states or countries with ungovernable areas have proven to be the most important safe havens (Lee 1988). Another collective action problem involves hostage taking. Maintaining a global convention of not conceding to terrorists' ransom 
demands is especially troublesome as some countries view some hostages as too important to leave in captivity. Countries not adhering to a no-concession policy send a signal to hostage takers that abducting the right hostage can be profitable. Concessions by one country reduce the credibility of other countries' stated no-concession policy. Another terrorism-related collective action worry arises as targeted countries overspend on defensive measures in an attempt to transfer terrorist attacks abroad, while these countries underspend on purely public proactive measures as a way to free ride on the actions of others (Arce 2013; Sandler 2005). Gathering intelligence on common terrorist threats presents coordination problems that targeted countries do not address efficiently owing to the public good aspects of intelligence. Ironically, terrorist groups appear to be more astute than governments in managing their collective action concerns as these groups form networks to assist one another.

The overuse of antibiotics has led to antibiotic-resistant superbugs that pose dire threats to current and future generations. The creation and control of superbugs represents an intergenerational collective action problem. Past and current generations created the problem by overusing antibiotics, not using treatments as instructed, or both. Moreover, the current generation needs to be sufficiently altruistic to future generations to invest enough in the discovery of new antibiotics. The sequence of generations means that future generations cannot meet and bargain with the current or previous generations to use antibiotics responsibly. Many health-based collective action issues possess an intergenerational component. Consider vaccinations to achieve herd immunity to eradicate an infectious disease. Once a disease is eradicated, current and future generations are protected and do not have to get booster shots. Even one country can keep the world from obtaining herd immunity for some disease. As the threshold of herd immunity is approached for some disease, incentives to get vaccinated are reduced because the chance of becoming infected goes down. Hence, for herd immunity, incentives to act become less imperative from the individual viewpoint as the goal becomes more attainable. Ironically, social incentives grow in importance as the achievement of herd immunity nears the threshold. Such perverse incentives plague other collective action problems.

Nuclear weapons proliferation is another bothersome collective action problem of profound importance. This concern is particularly difficult to handle because peaceful uses of nuclear reactors exist, thus the true intent of the suspected proliferator cannot be known with certainty. Scientists in a nuclear country can supply needed information to countries striving to develop nuclear weapons. Moreover, companies in other countries may supply dual-use technologies and needed equipment for a profit, despite the negative externalities imposed on others. Once a country nears or crosses the nuclear threshold, some powerful country must assume the burden of destroying the proliferators' nuclear capabilities. This is usually done by the most-threatened country.

Protecting the biodiversity of the planet is another collective action problem with intergenerational ramifications. Currently, the poaching of white rhinoceros in South Africa is causing that species to face extinction unless countries come to the aid of South Africa, which has not been able to stem the problem. One solution is to transfer some of the endangered species to another part of Africa that is able to protect against poaching. Many unique species and habitats are located in countries without sufficient resources to preserve such precious assets unless assisted by other countries. This need for shoring up or outside help raises a free-riding problem associated with a PD game.

The list of collective action problems is long, varied, and growing. 


\section{Concluding remarks}

In his celebrated book, Olson (1965) set himself an impossible task to distill the principles of collective action down to eight simple maxims that could capture all situations. The strategic interactions involving collective action include substitutes and complements ${ }^{16}$ in sequential, simultaneous, or repeated games. As such, no universal set of maxims can be stated that capture the variety of utility functions, cost functions, aggregation technologies, benefit rivalry, and participation costs.

By way of summary, Table 2 lists considerations that can invalidate Olson's (1965) maxims. For example, the provision of a best-shot public good is independent of group

Table 2 Selected factors working against Olson's propositions

Size of group

Group size inhibits group formation

Coalition's benefit share does not fall with group size

Aggregation technology (e.g. best shot)

Absence of participation costs

Increased group size and smaller provision

Income normality and pure public good

Exclusion mechanism and partial rivalry of benefits

Nonrivalry of collective benefits

Group size and suboptimality

Aggregation technology (weakest link, homogeneous tastes and endowments)

Collective club goods

Absence of complementary joint products

Group composition

Exploitation hypothesis: small exploiting the large

Some strategic assumptions (e.g. leader-follower behavior)

Commons problems or congestion problem

Agents' preferences run counter to agents' endowments

Heterogeneous group and some collective action

Aggregation technology (e.g. weakest link and unequal endowments)

Large rivalry of benefits

Homogeneous group are more apt to form

Presence of participation costs

Imperfect information

Aggregation technology (e.g. best shot)

\section{Institutional recommendations}

Selective incentives

Substitutability among joint products that can be produced separately

Institutional design

High transaction costs

Multiple stages

${ }^{16}$ The impact of leader-follower behavior on burden sharing and total output depends on the presence of strategic substitutes or complements. Possible combinations are even richer when mixed cases are considered—see Arce and Sandler (2009). 
size, provided that one sufficiently capable supplier privileges the group. Despite exceptions to Olson's collective action principles, they remain valid in many essential stylized cases-e.g. a pure commons or a pure public good-that represent numerous real-world situations. His provocative maxims motivated 50 years of research, experiments, and empirical studies that have sharpened everyone's understanding of collective action. If his propositions had been universally true, little of this research would have followed Olson's seminal work.

Open Access This article is distributed under the terms of the Creative Commons Attribution License which permits any use, distribution, and reproduction in any medium, provided the original author(s) and the source are credited.

\section{References}

Andreoni, J. (1988). Privately provided public goods in a large economy: The limits of altruism. Journal of Public Economics, 35(1), 57-73.

Andreoni, J., \& McGuire, M. C. (1993). Identifying the free riders: A simple algorithm for determining who will contribute to a public good. Journal of Public Economics, 51(3), 447-454.

Arce, D. G. (2013). Collective action and (counter) terrorism. In M. Rekoulak, L. Razzolini, \& W. F. Shughart II (Eds.), The Elgar companion to public choice (2nd ed., pp. 494-506). Edward Elgar: Cheltenham.

Arce, D. G., \& Sandler, T. (2009). Strategic aspects of terrorism. In N. Memon, J. D. Farley, D. L. Hicks, \& T. Rosenorn (Eds.), Mathematical methods in counterterrorism (pp. 333-348). Wien: Springer.

Bagnoli, M., \& McKee, M. (1991). Voluntary contribution games: Efficient private provision of public goods. Economic Inquiry, 29(2), 351-366.

Bergstrom, T. C., Blume, L., \& Varian, H. (1986). On the private provision of public goods. Journal of Public Economics, 29(1), 25-49.

Boadway, R. W., \& Bruce, N. (1984). Welfare economics. Cambridge, MA: Basil Blackwell.

Buchanan, J. M. (1965). An economic theory of clubs. Economica, 32(1), 1-14.

Chamberlin, J. (1974). Provision of collective goods as a function of group size. The American Political Science Review, 68(2), 707-716.

Cornes, R. (1993). Dyke maintenance and other stories: Some neglected types of public goods. The Quarterly Journal of Economics, 108(1), 259-271.

Cornes, R., \& Sandler, T. (1984). Easy riders, joint production, and public goods. The Economic Journal, 94(3), 580-598.

Cornes, R., \& Sandler, T. (1994). The comparative static properties of the impure public good model. Journal of Public Economics, 54(3), 403-421.

Cornes, R., \& Sandler, T. (1996). The theory of externalities, public goods, and club goods (2nd ed.). Cambridge: Cambridge University Press.

Dixit, A., \& Olson, M. (2000). Does voluntary participation undermine the Coase theorem? Journal of Public Economics, 76(3), 309-335.

Dixit, A., Skeath, S., \& Reiley, D. H. (2009). Games of strategy (3rd ed.). New York: W. W. Norton \& Company.

Dougherty, K. (2003). Public goods theory from eighteenth century political philosophy to twentieth century economics. Public Choice, 117(3-4), 239-253.

Esteban, J., \& Ray, D. (2001). Collective action and group size paradox. The American Political Science Review, 95(3), 663-672.

Ferguson, W. F. (2013). Collective action and exchange: A game-theoretic approach to contemporary political economy. Stanford, CA: Stanford University Press.

Hardin, G. (1968). The tragedy of the commons. Science, 162, 1243-1248.

Hardin, R. (1982). Collective action. Baltimore: Johns Hopkins University Press.

Harrison, G. W., \& Hirshleifer, J. (1989). An experimental evaluation of weakest link/best shot models of public goods. The Journal of Political Economy, 97(1), 201-223.

Helsley, R. W., \& Strange, W. C. (1991). Exclusion and the theory of clubs. The Canadian Journal of Economics, 24(4), 888-899. 
Hirshleifer, J. (1983). From weakest-link to best-shot: The voluntary provision of public goods. Public Choice, 41(3), 371-386.

Lee, D. R. (1988). Free riding and paid riding in the fight against terrorism. The American Economic Review, $78(2), 22-26$.

Libecap, G. D. (2014). Addressing global environmental externalities: transaction costs considerations. Journal of Economic Literature, 52(2), 424-479.

Libecap, G. D., \& Wiggins, S. N. (1984). Contracting responses to the common pool: Prorationing of crude oil production. The American Economic Review, 74(1), 87-98.

Marwell, G., \& Oliver, P. (1993). The critical mass in collective action: A micro-social theory. New York: Cambridge University Press.

McGuire, M. C. (1974). Group size, group homogeneity, and the aggregate provision of a pure public good under Cournot behavior. Public Choice, 18(1), 107-126.

Mueller, D. C. (2003). Public choice III. Cambridge: Cambridge University Press.

Olson, M. (1965). The logic of collective action. Cambridge, MA: Havard University Press.

Olson, M., \& Zeckhauser, R. (1966). An economic theory of alliances. The Review of Economics and Statistics, 59(3), 266-279.

Ostrom, E. (1987). The implications of the logic of collective inaction for administrative theory. Unpublished manuscript. Indiana University, Department of Political Science.

Ostrom, E. (1990). Governing the commons: The evolution of institutions for collective action. New York: Cambridge University Press.

Ostrom, E. (2000). Collective action and the evolution of social norms. The Journal of Economic Perspectives, 14(3), 137-158.

Palfrey, T. R., \& Rosenthal, H. (1984). Participation and the provision of discrete public goods: A strategic analysis. Journal of Public Economics, 24(2), 171-193.

Pecorino, P. (2015). Olson's Logic of Collective Action at fifty. Public Choice, 162(3-4), $243-262$.

Pecorino, P., \& Temimi, A. (2008). The group size paradox revisited. Journal of Public Economic Theory, 10(5), 785-799.

Runge, C. F. (1984). Institutions and the free rider; the assurance problem in collective action. The Journal of Politics, 46(1), 154-181.

Sandler, T. (1992). Collective action: Theory and applications. Ann Arbor: University of Michigan Press.

Sandler, T. (1997). Global challenges: An approach to environmental, political, and economic problems. Cambridge: Cambridge University Press.

Sandler, T. (2004). Global collective action. Cambridge: Cambridge University Press.

Sandler, T. (2005). Collective versus unilateral responses to terrorism. Public Choice, 124(1-2), 75-93.

Sandler, T. (2013). Buchanan clubs. Constitutional Political Economy, 24(4), 265-285.

Sandler, T. (2015). Strategic aspects of difficult global challenges. Unpublished manuscript. University of Texas at Dallas, Center for Global Collective Action.

Sandler, T., \& Arce, D. G. (2003). Pure public goods versus commons: Benefit-cost duality. Land Economics, 79(3), 355-368.

Sandler, T., \& Posnett, J. W. (1991). The private provision of public goods: A perspective on neutrality. Public Finance Quarterly, 19(1), 22-42.

Sandler, T., \& Tschirhart, J. (1980). The economic theory of clubs: An evaluative survey. Journal of Economic Literature, 18(4), 1481-1521.

Sandler, T., \& Tschirhart, J. (1997). Club theory: Thirty years later. Public Choice, 93(3-4), 335-355.

Schotter, A. (2008). The economic theory of social institutions. New York: Cambridge University Press.

Solomon, B. (2007). The political economy of peacekeeping. In T. Sandler \& K. Hartley (Eds.), Handbook of defense economics: Defense in a globalized world (pp. 741-774). Amsterdam: North-Holland.

Taylor, M. (1987). The possibility of cooperation. New York: Cambridge University Press.

Tullock, G. (1974). The social dilemma: The economics of war and revolution. Blacksburg, VA: University Publications.

Vicary, S. (1990). Transfers and the weakest link: an extension of Hirshleifer's analysis. Journal of Public Economics, 43(3), 375-394.

Vicary, S. (2009). The voluntary provision of a public good in an international commons. The Canadian Journal of Economics, 42(3), 984-996.

Vicary, S., \& Sandler, T. (2002). Weakest-link public goods: giving in-kind or transferring money. European Economic Review, 46(8), 1501-1520. 